
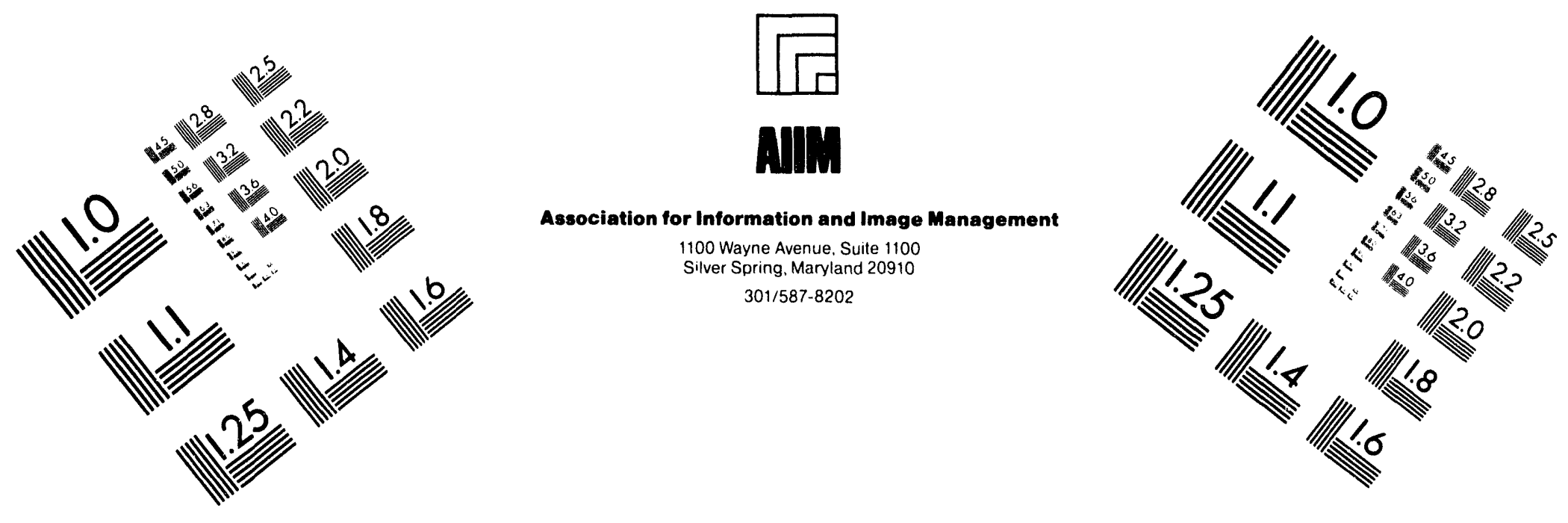

\title{
Centimeter
}

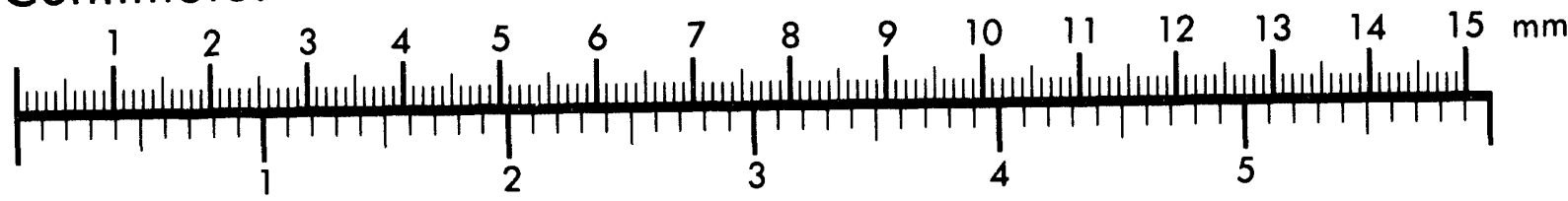
Inches
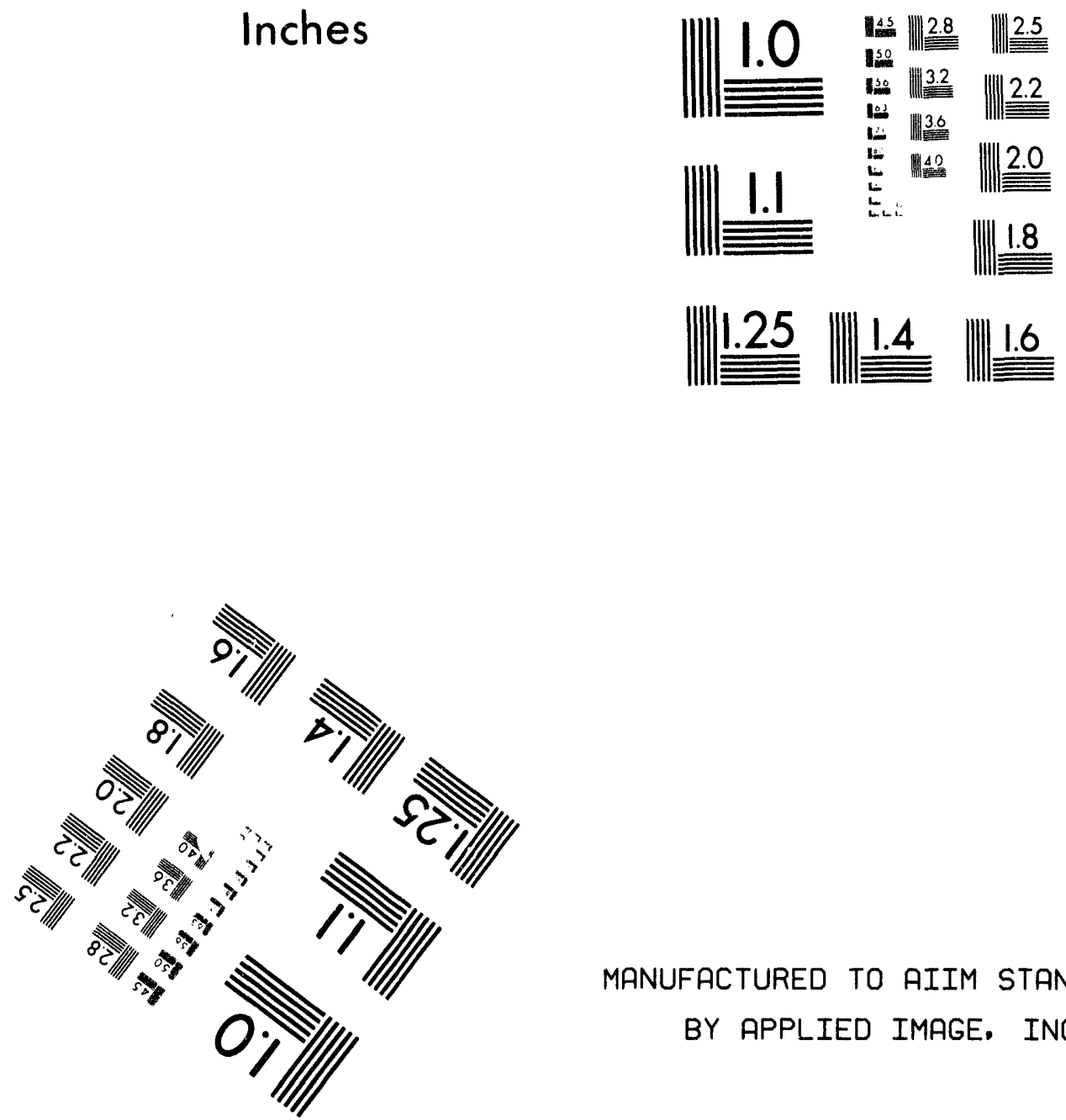

MANUFACTURED TO AIIM STANDARDS

BY APPLIED IMAGE, INC.

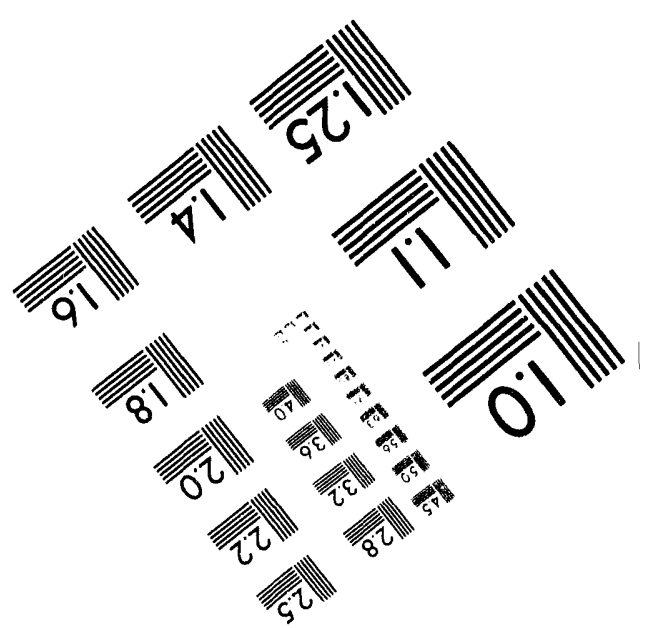



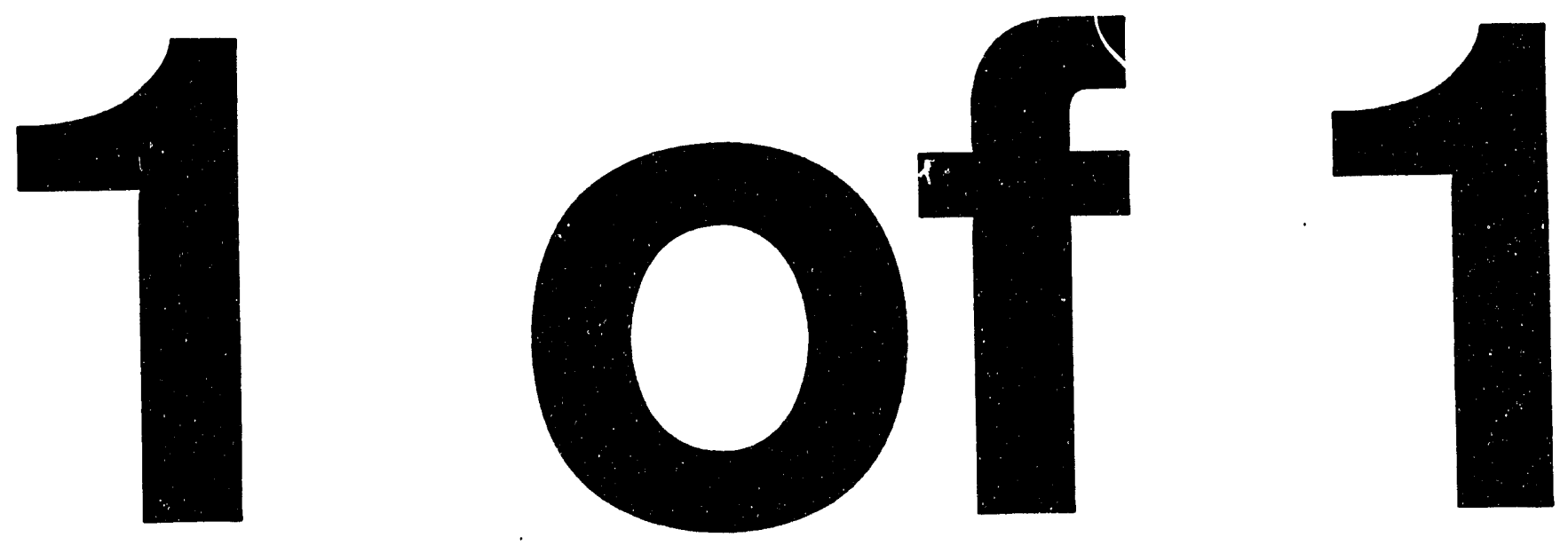


$$
\text { Conf }-9309413--1
$$

\title{
READINESS THROUGH RESEARCH
}

\section{SAMPLING AND ANALYSIS OF NATURAL GAS TRACE CONSTITUENTS}

\author{
by \\ Amir Attari \\ Sherman Chao
}

Paper Presented at

THE FIRST INTERNATIONAL OIL, GAS

\& PETROCHEMICAL CONGRESS

Isfahan, Iran

September 1993

INSTITUTE OF GAS TECHNOLOGY

3424 South State Street? Chicago, Illinols 60616 


\title{
SAMPLING AND ANALYSIS OF NATURAL GAS TRACE CONSTITUENTS
}

\author{
Amir Attari \\ Sherman Chao \\ Institute of Gas Technology (IGT) \\ 3424 South State Street \\ Chicago, II 60616 \\ USA \\ For Presentation at \\ The First International Oil, Gas \& Petrochemical Congress \\ September 1993, Isfahan, Iran
}

\begin{abstract}
Major and minor components of natural gas are routinely analyzed by gas chromatography (GC), using a thermal conductivity (TC). The best results obtained by these methods can report no better than 0.01 mole percent of each measured component. Even the extended method of analysis by flame ionization detector (FID) can only improve on the detection limit of hydrocarbons. The gas industry needs better information on all trace constituents of natural gas, whether native or inadvertently added during gas processing that may adversely influence the operation of equipment or the safety of the consumer. The presence of arsenic and mercury in some gas deposits have now been documented in international literature as causing not only human toxicity but also damaging to the field equipment. Yet, no standard methods of sampling and analysis exist to provide this much needed information.
\end{abstract}

In this paper we report the results of a three-year program to develop an extensive array of sampling and analysis methods for speciation and measurement of trace constituents of natural gas. A cryogenic sampler operating at near $200 \mathrm{~K}\left(-99^{\circ} \mathrm{F}\right)$ and at pipeline pressures up to $12.4 \times 10^{6} \mathrm{~Pa}(1800$ psig) has been developed to preconcentrate and recover all trace constituents with boiling points above butanes. Specific analytical methods have been developed for speciating and measurement of many trace components (corresponding to US EPA air toxics) by GC-AED and GC-MS, and for determining various target compounds by other techniques. Moisture, oxygen and sulfur contents are measured on site using dedicated field instruments. Arsenic, mercury and radon are sampled by specific solid sorbents for subsequent laboratory analysis. 


\section{INTRODUCTION}

The deregulation of the gas industry in the United States has caused some concern over the uniformity of gas quality and their environmental and processing implications. Contaminations from various sources may occur and transport through pipeline systems may cause a wider spread of the existing problems. In order to prevent these potential problems from happening the pipeline natural gas from various sources should be surveyed to assess the current situation and to predict and prevent the unforeseen difficulties.

Routine analysis of processed natural gas for calculation of heating value, specific gravity and compressibility (compression factor) has now been establisbed as an ordinary and necessary measurement practice by the gas industry world-wide. Automated gas chromatographs, which are now a shelf item from many' manufacturers, provide the needed gas composition with acceptable precision (repeatability) and even good accuracy if calibration gas of known uncertainty is used. These routine analyses, however, provide information only on major and minor components, i.e. $\mathrm{N}_{2}, \mathrm{CO}_{2}$, paraffins from $\mathrm{C}_{1}$ through $\mathrm{C}_{5}$ and all other hydrocarbons above $\mathrm{C}_{6}$ ( $\mathrm{C}_{6}$ plus) as if they were a single component. The lowest level of concentration afforded by this routine analysis is about 0.01 mole percent.

Below this 0.01 mole \% may lurk a whole population of gas components collectively classified as trace constituents. The major portion of trace constituents are naturally occurring species such as traces of paraffinic and aromatic hydrocarbons, $\mathrm{H}_{2} \mathrm{~S}$, organic sulfur compounds (the natural odorants), and traces of $\mathrm{H}_{2}$ and $\mathrm{He}$. Among them, the increasing levels of carbon dioxide, water content, $\mathrm{O}_{2}$ and heavy hydrocarbons are presenting clean-up problems for LNG plant operators. Arsenic and mercury have been found in some natural gas deposits. The presence of arsenic was noted when trialkylarsine sulfides, as a white deposit, was found on pressure regulation devices in natural gas distribution lines. Mercury was detected in Groningen gas after having accumulated in natural gas liquids recovery vessels and again, in Algeria because of the extensive damage it caused to the aluminum heat exchangers of Skikda LNG plant. There are also other trace species in processed natural gas which are inadvertently added by gas processing operations such as traces of various amines, ammonia, $\mathrm{NO}_{x}$, formaldehyde, halocarbons, mercury (from mercury spills), etc. Formaldehyde and oxides of nitrogen were detected after they were related to odor fading in odorized natural gas.

Whatever the sources of these components, it is to the benefit of the gas industry to obtain the required information on the quality of gas to avoid any potential problems. To provide this type of information, in August of 1989 the Gas Research Institute (GRI) sponsored a program at IGT to develop a safe sampling scheme and necessary analytical methods to survey the concentration of all constituents of natural gas, specifically those compounds likely to be found in natural gas that also appear on the EPA list of air toxic substances. This survey sought to provide comprehensive gas quality information on processed natural gas from several important gas producing areas of U.S. and Canada.

The work of this trace constituents survey include formulating a list of target trace components required for this program in reference to the list of hazardous air pollutants, devising a natural gas sampling train and sampling procedures to preserve and preconcentrate trace constituents in natural gas for subsequent analyses, developing analytical methods for both field and laboratory applications, and finally collecting samples from various selected sites and analyzing the samples to compile a data base for the gas industry. 


\section{RESULTS AND DISCUSSION}

Many types of selected target components listed below are routinely measured in this program. However, the characterization and quantitation is not limited to those components in the list. Any other component found in the screening analysis, which is conducted first, will also be characterized and its concentration measured.

- Non-hydrocarbons: $\mathrm{He}, \mathrm{H}_{2}, \mathrm{O}_{2}, \mathrm{~N}_{2}, \mathrm{CO}, \mathrm{CO}_{2}, \mathrm{H}_{2} \mathrm{O}, \mathrm{As}, \mathrm{Hg}$

- Hydrocarbons: $\mathrm{C}_{1}-\mathrm{C}_{14}$ paraffins, $\mathrm{C}_{2}-\mathrm{C}_{3}$ olefins, BTEX, PAH

- Oxygenated compounds: Acetone, methanol, glycols, aldebydes, phenols, cresols

- Nitrogen compounds: $\mathrm{NH}_{3}, \mathrm{NO} / \mathrm{NO}_{\mathbf{x}}$, amines, $\mathrm{N}$-heterocycles

- Halocarbons: Freons and landfill gas components $\left(C_{1}-C_{3}\right.$, cyclic, aromatic), PCBs

- Sulfur compounds: $\mathrm{H}_{2} \mathrm{~S}, \mathrm{SO}_{2}, \mathrm{COS}, \mathrm{CS}_{2}$, mercaptans and derivatives

- Organometallics: Volatile compounds of As, $\mathrm{Co}, \mathrm{Cu}, \mathrm{Fe}, \mathrm{Ge}, \mathrm{Hg}, \mathrm{Ni}, \mathrm{P}, \mathrm{Pb}, \mathrm{Sb}, \mathrm{Se}, \mathrm{Si}, \mathrm{Sn}$

- Others: NORM (Naturally Occurring Radioactive Materials including Radon)

Processed gases from various gas producing areas, representing different single or mixed geological formations in the United States are sampled at either the inlet or the terminus of NG pipelines.

The following types of samples are collected at each site:

- Whole gas samples

- Liquefied fractions (cryogenic sampling train at 200X)

- Lean gas (after the cryogenic sampler)

- Particulate samples (if present on the sampling train filter up-stream of sampler)

- Pipeline condensate (when available)

- Pipeline deposits (from brush-piggings, if available)

Samples are collected using different sampling techniques to preserve and/or preconcentrate the compounds of interest for later analysis in laboratory. An automatic insertion probe from Welker Engineering is used to place the tip of the probe at the center third of the pipeline to assure representative sampling. A proportional sampler from Welker Engineering is also used to sample pipeline gas over a long span of time to collect a representative whole gas sample. Gas cylinders internally coated with phenolic resin are used to collect pas samples, insuring the integrity of the reactive components of the gas sample, such as sulfur compounds.

For trace organic constituents a cryogenic system, which operates at $200 \mathrm{~K}\left(-99^{\circ} \mathrm{F}\right)$ and at line pressures up to $12.4 \times 10^{6} \mathrm{~Pa}$ (1800 psig) has been employed. The system is designed to condense, preconcentrate and recover all components that boil above butane's boiling point. This cryogenic sampler uses a heat exchange coil made of approximately 10 feet of 1/4 inch O.D. 316 S.S. tubing wound in a helical form, which is attached to a single ended 150-ml 316 S.S. sample cylinder through a Tee connector. The gas flows downward through the coil and cylinder and exits through a straight S.S. tubing. Two shut-off valves are installed at either end of each tubing above the level of chilling fluid. 
An immersion cooler (FTS Model FC-100) is used for constant temperature control of the cryogenic bath containing one part of methanol and 3 parts of isopropanol. Dry ice is used to accelerate the cooling rate and to reach the desired cryogenic temperature quickly. A Honda EM2200X electric generator is used to provide all power requirod for the immersion cooler and other field operations, if electric services is not available at a given sampling site

Solid sorbent are used to collect mercury, arsenic and radon in field for subsequent analysis in the IGT biboratory. Mercury is sampled at a flow rate of $1 \mathrm{~L} / \mathrm{min}$ using two $6 \mathrm{~mm} \mathrm{ID}$ sorbent tubes packed with $2.5 \mathrm{~cm}$ length of $1 \%$ gilded silica beads connected in series, and measured by thermal desorption with continuous atomic spectroscopic detection. Arsenic is sampled at a flow rate of $1 \mathrm{~L} / \mathrm{min}$ with a $6 \mathrm{~mm}$ tube packed with two $4 \mathrm{~cm}$ sections of either the HGR carbon or the FECL $\left(25 \% \mathrm{FeCl}_{3}\right)$ sorbent, and determined by $\mathrm{X}$-ray fluorescence (XRF) and atomic spectroscopic techniques, respectively. Radon is collected at a flow rate of $1.2 \mathrm{~L} / \mathrm{min}$ with two 2"x3" carbon cartridge and measured by Gamma ray spectroscopy.

A hygrometer from Stephens Analytical is used for moisture determination in a range of 10 to 6000 ppmv. The Delta $F$ trace oxygen analyzer is used with an Ascarite scrubbing tube to remove $\mathrm{CO}_{2}$ interferents from the tested natural gas. This on-line instrument provides an accurate and fast measurement of oxygen with a range of 1 to 1000 ppmv. A Scintrex sulfur analyzer, Model OVD-229, from Heath Consultants, Inc. is used to monitor the concentration of odorants and $\mathrm{H}_{2} \mathrm{~S}$ in natural gas at a concentration level of 0.1-10 ppmv. An extended-frame van, a Ford Econoline 150, is fitted with racks to carry sampling devices and monitoring instruments to the field.

In the laboratory, the cryo-trap sample collected in the field is expanded twice at $0^{\circ} \mathrm{C}$ and $25^{\circ} \mathrm{C}$. The residual condensate in the trap is rinsed and recovered with $5 \mathrm{ml}$ of hexadecane. Selected samples of whole gas, pipeline condensate, expansion gas, cryo-trap condensate and washings are analyzed. The composition of these samples are screened, characterized and measured according to the following analytical procedures.

- ASTM 1945 and 1946 methods for major and minor components in gas

- Modified GPA extended hydrocarbons analysis with capillary GC column

- Target halocarbons analysis by GC-ELCD (Hall-Effect)

- Trace sulfur compounds analysis by Flame Pbotometric Detector (FPD) and/or Sulfur Chemiluminescence Detector (SCD)

- Target nitrogen compounds analysis by Gas Chromatograph-Atomic Emission Detector (GC-AED)

- Target oxygen containing compounds analysis by GC-AED and by a modified EPA TO-11 analytical method developed for aldehydes and ketones in air

- Elemental speciation by GC-AED

- Compound identification by GC-Mass Spectrometer (GC-MS) analysis

- PAHs analysis of condensate and washings by HPLC

- PCBs analysis of condensate and washings by GC-Electron Capture Detector (GC-ECD)

- NO/NOx analysis of whole gas samples by chemiluminescence

Gas chromatographs equipped with a variety of columns and detectors for specific analytical purposes are used for this program in IGT laboratories. Two standard GC columns, DB-5 and DB-Wax columns are employed for analysis of non-polar and polar comrounds, respectively. GC-AED and GC-MS are two most 
important techniques for qualitative identification and measurement of uncommon trace species. Laboratory preconcentration techniques are utilized, when needed, to separate interferents from the sample and to improve the detection limits for given components.

To date, we have successfully completed our survey work of the following pas producing areas:

- On-shore Texas-Louisiana Gulf Coast

- Off-shore Texas-Louisiana Gulf Coast

- Nabama coal-seam

- Abo Field - New Mexico

- Anadarko Basin

- Arkoma Basin

- Permian Basin

- Appalachian

- Appalachian shale formation

- Mlinois basin

- Mid-continental

- San Juan Basin

- Wyoming gas

- Rocky Mountain

- Canadian gas

Survey results plus field operating data, sampling parameters and other pertinent information are presented later in this report.

\section{CONCLUSION AND SUMMARY}

A project, sponsored by GRI, was initiated to develop a set of sampling and analytical schemes to survey the concentration of all measurable trace constituents of natural gas that may be of operational or environmental concern.

Many sampling and analytical techniques have been developed in this program to characterize and measure natural gas trace constituents. Specific analytical methods have been developed for speciating and measuring trace components by GC-AED and GC-MS, and for determining various target compounds by other techniques. Moisture, oxygen and sulfur contents are measured on site using dedicated field instruments. Arsenic, mercury and radon are sampled by specific solid sorbents for subsequent laboratory analysis. A long list of other components of interest are measured in the cryogenic condensate and whole gas samples.

We plan to publish, in a single volume, all of the sampling and analytical methods that were developed for this project in late 1993.

A shon list of target components that we are surveying at the present time are listed in Table 1.

Table 2. presents data on the concentration range of the various components we have measured in processed natural gas sampled from above 15 producing areas. 


\section{Table 1. Short List of Target Components And Their Method Detection Limits}

\begin{tabular}{|c|c|c|c|c|c|}
\hline NON-HYDROCARBONS & $\mathrm{MDL}{ }^{1}$ & $\mathrm{RP} \%{ }^{2}$ & NON-HIYDROCARBONS & $\mathrm{MDL}$ & RP\% \\
\hline Oxygen-monitor, ppmv & 1 & 5 & Arsenic $F E C L, \mu g / \mathrm{m}^{3}$ & $\mathbf{s}$ & 15 \\
\hline Oxygen,GC, $\%$ & 0.03 & 1 & Arsenic - HGR, $\mu \mathrm{g} / \mathrm{m}^{3}$ & so & 10 \\
\hline Moisture, ppmv & 10 & 5 & Mercury, $\mu g / \mathrm{m}^{3}$ & 0.01 & 10 \\
\hline Helium, \% & 0.002 & 1 & & & \\
\hline Hydrogen, \% & 0.002 & 1 & NO, ppmv & 0.05 & 10 \\
\hline Nitrogen, $\%$ & 0.03 & 1 & NOx, ppmv & 0.05 & 10 \\
\hline Carton dioxide, $\%$ & 0.03 & 1 & Radon, pcill & 1 & 15 \\
\hline Carbon monoxide, $\%$ & 0.03 & 1 & & & \\
\hline MAJOR HYDROCARBONS & $\frac{\mathrm{MDL}}{[\%]}$ & RP\% & $\begin{array}{l}\text { CS PLUS HYDROCARBONS } \\
\text { Aliphatics }\end{array}$ & $\frac{\mathrm{MDL}}{\text { [ppmv] }}$ & $\mathbf{R P} \%$ \\
\hline Methane & 0.03 & 2 & Cyclopentane & 1 & 3 \\
\hline Ethane & 0.03 & 2 & Hexanes & 0.2 & 5 \\
\hline Ethene & 0.03 & 2 & Methyl cyclopentane & 0.2 & 5 \\
\hline Ethyne (Acetylene) & 0.002 & 2 & Cyclohexane & 0.2 & 5 \\
\hline Propane & 0.002 & 2 & Heptanes & 0.2 & s \\
\hline Propene & 0.002 & 2 & Methyl cyclohexane & 0.2 & 5 \\
\hline Propyne & 0.002 & 2 & Octanes & 0.1 & 10 \\
\hline Propadiene & 0.002 & 2 & Nonanes & 0.1 & 10 \\
\hline i-Butane & 0.003 & 2 & Decanes & 0.1 & 10 \\
\hline n-Butane & 0.003 & 2 & Undecanes & 0.1 & 10 \\
\hline j-Butene & 0.003 & 2 & Dodecanes & 0.1 & 10 \\
\hline iso-Butene & 0.003 & 2 & Tridecanes & 0.1 & 10 \\
\hline trans-2-Butene & 0.003 & 2 & Tetradecanes & 0.1 & 10 \\
\hline cis-2-Butene & 0.003 & 2 & Aromatics & & \\
\hline Butadiene & 0006 & 2 & Benzene & 0.2 & 10 \\
\hline neo-Pentane & 0.001 & 2 & Toluene & 0.1 & 10 \\
\hline i-Pentane & 0.001 & 2 & Xylenes & 0.1 & 10 \\
\hline n-Pentane & 0.001 & 2 & Ethylbenzene & 0.1 & 10 \\
\hline Pentenes & 0.001 & 2 & C3-Benzenes & 0.1 & 10 \\
\hline \multirow[t]{2}{*}{ C6 Plus } & 0.002 & 5 & Naphthalene & 0.1 & 10 \\
\hline & & & PAHs & 0.02 & 10 \\
\hline
\end{tabular}

\begin{tabular}{|c|c|c|c|c|}
\hline SULFUR COMPOUNDS & $\frac{M D L}{\text { [ppmv] }}$ & $\mathrm{RP} \%$ & HALOCARBONS & $\frac{\text { MDL }}{\text { [ppmv] }}$ \\
\hline Hydrogen sulfide & $1(0.1)$ & $10(10)$ & 7 Freons & 0.05 \\
\hline Sulfur dioxide & 0.02 & 5 & Vinyl chloride & 0.05 \\
\hline 5 Mercaptans & $0.02(0.1)$ & $s(10)$ & 27 other target compounds & 0.05 \\
\hline s Sulfides (COS, DMS,etc.) & $0.02(0.1)$ & $s(10)$ & PCBs(Arochlors) & 0.01 \\
\hline 16 Disulfides (CS2,DMDS,etc.) & 0.02 & s & PCBs(Congenets) & 0.001 \\
\hline 3 Trisulfides & 0.02 & 5 & & \\
\hline 8 Aromatics (Thiophene,etc.) & 0.02 & 5 & & \\
\hline Thiophare & 0.02 & 5 & & \\
\hline
\end{tabular}

Note: GC-FPD or GC-Chemiluminescence, ( ) denotes by Scintrex OVD-229
Note: Volatile halocarbons by GC-ELCD \& GC-MS PCBs by GC-ECD \& GC-ELCD on candensates from cryo-trap. 
Table 1. Short List of Target Components And Their Method Detection Limits-p.2

\begin{tabular}{|c|c|c|c|c|c|}
\hline NITROGEN-COMPOUNDS & MDLLPDim & $\mathrm{BP} \%$ & QXYGENATES & Moulopm & $\mathrm{RP} \%$ \\
\hline Ammonia & 2 & 15 & 2 Alkene Oxide & 1 & 12 \\
\hline 12 Alkyl amines & 0.5 & 10 & S Aldehydes (Formaldehyde, etc.) & $1(0.01)$ & $12(10)$ \\
\hline Acetonitrile & 0.5 & 10 & Methanol & 1 & 12 \\
\hline $\begin{array}{l}2 \text { N-beterocycies (pyridine \& } \\
\text { pyrrole) }\end{array}$ & 0.5 & 10 & Acetone & $1(0.01)$ & $12(1$ \\
\hline 2 Ethanolamines & 0.5 & 10 & $\begin{array}{l}3 \text { Glycols } \\
\text { Maleic Anhydride } \\
\text { Phenol \& } 3 \text { Cresols }\end{array}$ & $\begin{array}{l}1 \\
1 \\
1\end{array}$ & $\begin{array}{l}12 \\
12 \\
12\end{array}$ \\
\hline
\end{tabular}

Note: Crya-trap GC-AED analysis, Stabiluax-DB column for nitrogen, md DB-Wax \& DB-5 for oxygen,

( ) denotes $\mathrm{MDL}$ and RP\% of aldehyde and ketone analysis by DNPH MPLC .

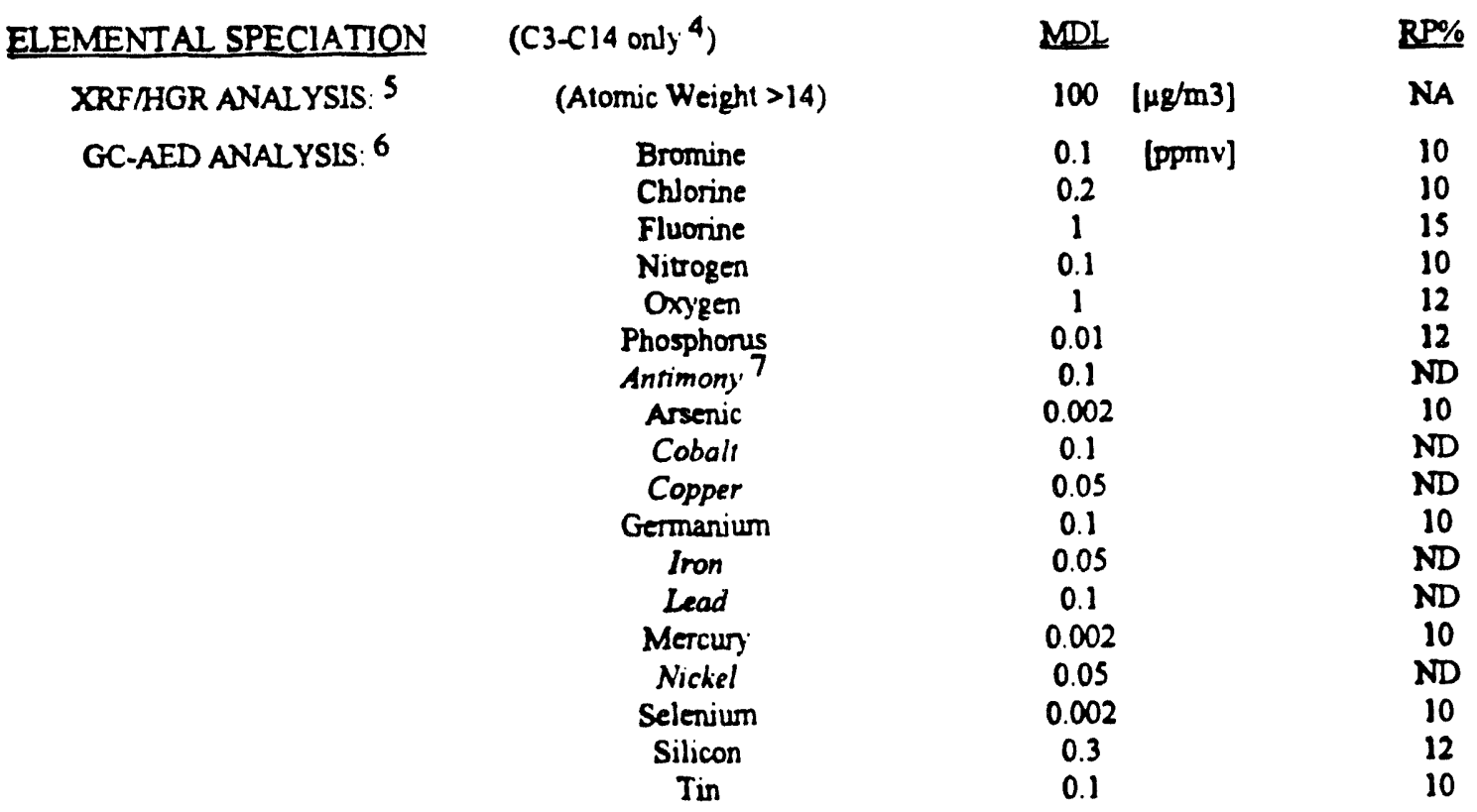

Notes: 1. "MDL"= Method Detection Limit; It may vary as analysis and sampling parameters change.

2. $" R P \% "=\%$ Relative Precision (2 S.D.) at a concentration 20 times of the $\mathrm{MDL}$.

3. For $\mathrm{CS}-\mathrm{Cl} 4$ components, expansion gas, ambient condensate and washing samples from cryogenic traps were anslyzed by capillary $G C$ and the results summed up.

4. Lower detection limits (10-1000X) are attainsble, if expansion gas, umbient condensate and washing amples from cryogenic traps were analyzed and the results summed up.

5. X-Ray Fluorescence semi-quantitative analysis of trace elements collected on HGR curbon sorbent.

6. GC-AED aralysis of 20 trace elements present in gas samples.

7. Only qualitative or semi-quantitative analysis can be done on those elements denoted in thalics.

8. $" N A "=$ Not Applicable, "ND" $=$ Not Determined 
Table 2. Trace Constituents in Natural Gas: Concentration Range And Median

\begin{tabular}{|c|c|c|c|c|c|c|}
\hline Major Components: & Range & Median & C6 Plus Hy & ydrocarbons: & Range & Median \\
\hline Moisture, ppmv (LbMMMCF) & $<10-2600$ & 105 & Aliphatics: & Cyclopentane & $<1-33$ & 7 \\
\hline Oxyzen, ppmv & $2.9-42$ & 8.1 & & Hexanes & $4.2-1156$ & 175 \\
\hline Helium & $0.002-0.780$ & 0.034 & & Methyl cyclopentane & $\phi .2-115$ & 20 \\
\hline Hydrogen & $<.002 \cdot 0.120$ & 0.006 & & Cyclohexane & $\$ .2-109$ & 30 \\
\hline Nitrogen & $0.22-2.96$ & 1.20 & & Heptanes & $\varnothing 0.2-433$ & 90 \\
\hline Carbon Dioxide & $0.07-2.62$ & 0.56 & & Methyl cyclohexane & $<0.2-133$ & 22 \\
\hline Methane & $81.1-98.5$ & 92.9 & & Octanes & $<0.1-280$ & 46 \\
\hline Ethane & $0.09-11.8$ & 3.06 & & Nonanes & $\$ .1-280$ & 12 \\
\hline Propane & $0.005-3.95$ & 0.46 & & Decanes & $\infty .1-120$ & 3.4 \\
\hline Isobutane & $<0.003-0.369$ & 0.063 & & Undecanes & $\infty .1-20$ & 1.5 \\
\hline n-Butane & $<0.003-0.822$ & 0.051 & & Dodecanes & $\$ .1-2.1$ & .055 \\
\hline Neopentane & $8.001-0.004$ & $<0.001$ & & Tridecanes & $\$ .1 \cdot 0.6$ & $\$ .1$ \\
\hline Isopentane & $<.001-0.18$ & 0.02 & & Tetradecanes & $\$ .1-0.1$ & 4.1 \\
\hline n-Pentane & $<0.001-0.16$ & 0.02 & & & & \\
\hline \multirow[t]{3}{*}{ C6 \& Heavier } & $<0.002-0.226$ & 0.042 & Aromatics: & Benzene & $<0.2-471$ & 7 \\
\hline & & & & Toluene & $<.0 .1-100$ & 7 \\
\hline & & & & Ethylbenzene & $<.1-15$ & 0.1 \\
\hline Calculated Properties: & & & & Xylenes & $4.1-12$ & 0.8 \\
\hline Relative Density & $0.561-0.685$ & 0.595 & & C3 - benzenes & $4.1 \cdot 1.5$ & 4.1 \\
\hline Compressibility & $0.9969-0.9980$ & 0.9978 & & Naphthalenes & 4.1 & $\$ .1$ \\
\hline $\begin{array}{l}\text { Dry Gross Heating Value at } \\
14.73 \text { osia. BTU/SCF }\end{array}$ & $988-1193$ & 1023 & & PAHs & $\varnothing .02$ & $\varnothing .02$ \\
\hline
\end{tabular}


Table 2. Trace Constituents in Natural Gas: Concentration Range And Median (cont.)

\begin{tabular}{|c|c|c|}
\hline Sulfur Components: & Range & Median \\
\hline & \multicolumn{2}{|c|}{ [ppmv] } \\
\hline Hydrogen sulfide & $<0.1-6$ & 0.2 \\
\hline Cerbonyl sulfide & $<0.02$ & $<0.02$ \\
\hline Carbon disulfide & $<0.02$ & $<0.02$ \\
\hline Methyl mercapten & $<0.02-0.15$ & $<0.02$ \\
\hline Ethyl mercaptan & $<0.02-0.16$ & 0.04 \\
\hline i - Propyl mercaptan & $<0.02 \cdot 0.41$ & 0.02 \\
\hline n-Propyl mercaptan & $<0.02-0.02$ & $<0.02$ \\
\hline t - Butyl mercaptan & $<0.02-0.08$ & $\$ 0.02$ \\
\hline Dimethyl sulfide & $\varangle .02-0.5$ & $<0.02$ \\
\hline Methyl ethyl sulfide & $<0.02-0.06$ & $<0.02$ \\
\hline Diethyl sulfide & $\varnothing 0.02-0.05$ & $<0.02$ \\
\hline Dimethyl disulfide & $\$ 0.02-0.8$ & 40.02 \\
\hline Other disulfides & $\varangle .02-0.48$ & 8.02 \\
\hline Trisulfides & $40.02-0.4$ & $<.02$ \\
\hline Residual sulfides (Polysulfides) & $<0.02-0.75$ & 0.09 \\
\hline
\end{tabular}

\begin{tabular}{lcc} 
Nitrogen Compounds: & Range & Median \\
\hline [ppmv] & \\
Ammonia & $\varangle$ & $\varangle$ \\
17 other target compounds & $\varangle .5$ & $\varangle .5$ \\
Other compounds & $\varangle .5$ & $\varangle .5$
\end{tabular}

Oxygenates:

Methanol $1-92$

Acetone $<1-24<1$

15 Other target compounds $<1$

Other compounds (No.) $\quad<1.6<1$

Halocarbons:

$\begin{array}{lll}35 \text { target compounds } & <0.1 & \$ 0.1 \\ \text { PCBs } & \varangle 0.01 & 40.01 \\ \text { Other compounds } & \varangle .1 & 40.1\end{array}$

Other Elememts and Coinpounds:

\begin{tabular}{|c|c|c|c|c|}
\hline Total Arsenic, ug/m ${ }^{3}$ & $<s$ & $<5$ & NOx, ppmv & $\$ .05-130$ \\
\hline Total Mercury, $\mathrm{ve} / \mathrm{m}^{3}$ & 4.2 & $ه .2$ & Radon, $\mathrm{pCi} \Omega$ & $<1 .>23^{\circ}$ \\
\hline
\end{tabular}

- Because breakthrough occurred, the radon content in one sample cannot be uccurntely measured, but estimated as higher than $23 \mathrm{pCi} \Omega$. 

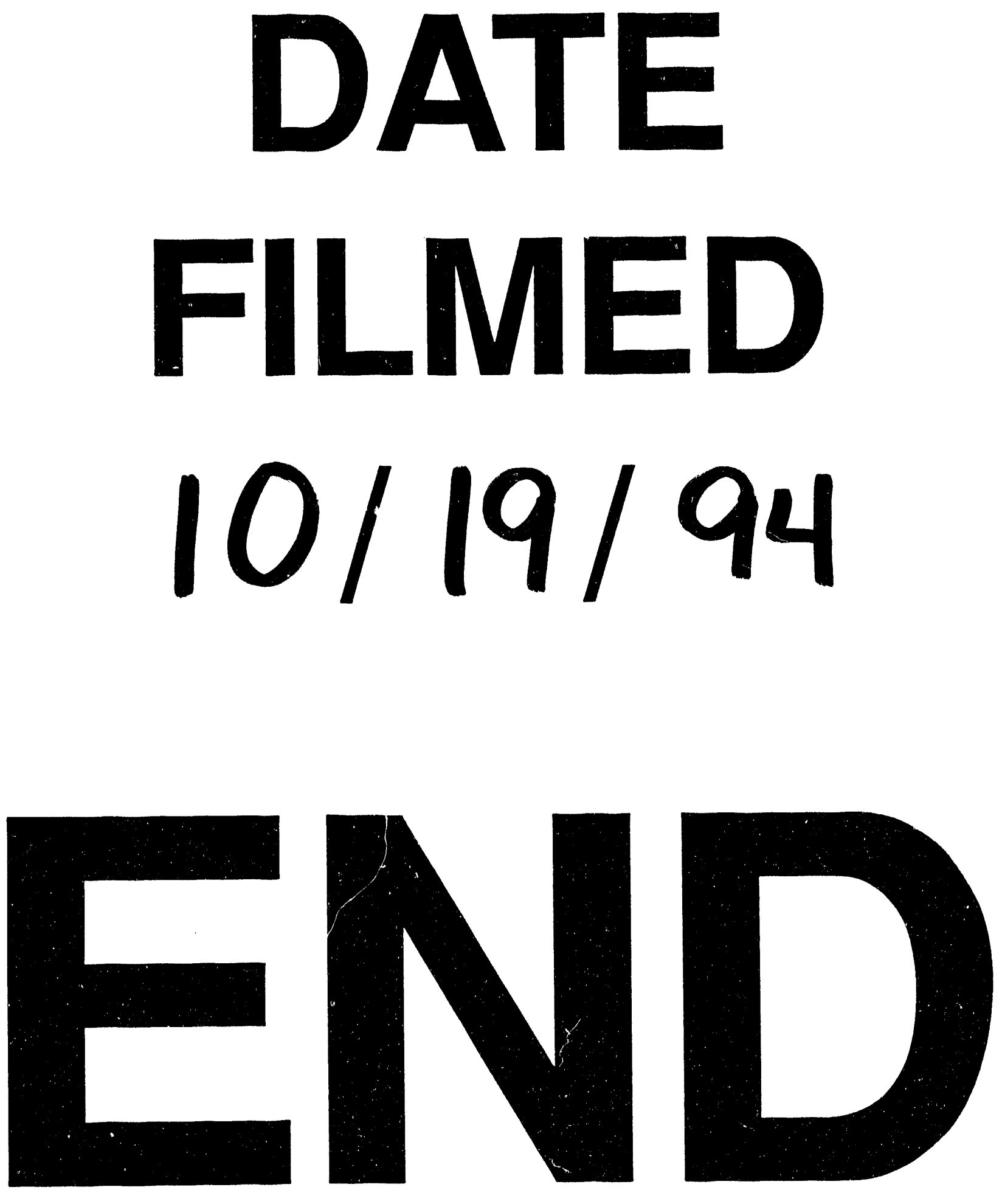